\title{
Las políticas democráticas de la industria del juego. Un estudio comparativo de América del Norte
}

\author{
Hugo RANGel TORRIJO*
}

\section{RESUMEN}

En este estudio se analiza la industria del juego en América del Norte y las políticas públicas, legislación, fiscalidad, transparencia y su carácter público tendente al bienestar común, incluyendo la atención de la ludopatía. ${ }^{1}$ Se analiza su perfil democrático. Se muestra que México cuenta con agudas deficiencias y contradicciones. En contraste, Estados Unidos y Canadá han construido este sector para el beneficio público a través de instituciones transparentes y principios más democráticos. En este sentido, se argumenta que la reestructuración de esta industria es una tarea pendiente de la construcción democrática en México.

Palabras clave: industria de casinos, lotería, democracia, Norteamérica, políticas públicas.

\section{AbSTRACT}

This study analyzes the gaming industry in North America and public policies, legislation, tax status, transparency, and the industry's public nature for the common good, including care for gambling addiction. Analyzing its democratic profile, it shows that Mexico suffers from sharp deficiencies and contradictions in this terrain. In contrast, the United States and Canada have constructed this sector for the public benefit through transparent institutions and more democratic principles. The author argues that restructuring this industry is necessary for building democracy in Mexico.

Key words: casino industry, lottery, democracy, North America, public policies.

\footnotetext{
* Universidad de Guadalajara y UQAM, hugo.rangel@mail.mcgill.ca.

${ }^{1}$ Esta investigación sobre la industria del juego en México, Estados Unidos y Canadá se realizó de 2007 a 2011; sin embargo, para profundizar en aquélla se ha incluido información reciente sobre el tema de los casinos, así como algunos antecedentes.
} 
El arte de gobernar consiste en tomar la mayor cantidad posible de dinero de una categoría de ciudadanos para dársela a otra VOLTAIRE

\section{INTRODUCCIÓN}

La industria del juego es una de las de mayor crecimiento en el mundo y una de las más rentables. Su historia ha estado ligada al crimen y al vicio, por lo que se prohibió en Norteamérica en el siglo XIx. Sin embargo, su reapertura ha estado acompañada de la reestructuración (vía políticas y legislaciones), la cual ha limitado este vínculo con el crimen. Pero, ¿cómo se organizan los casinos y loterías en los países de América del Norte? La industria del juego ha crecido con un marco regulatorio y legal, acorde con el desarrollo democrático de los países. En Estados Unidos y Canadá, su desarrollo ha sido producto de políticas públicas que han aprovechado la industria para financiar proyectos de cada vez mayor envergadura. El enfoque comparativo que aquí se presenta ofrece no sólo elementos de análisis, sino que también sirve como parámetro para emprender una tarea legislativa, así como las políticas públicas necesarias en México. Cabe mencionar que este tema ha sido escasamente examinado tanto por los analistas de políticas públicas como por los estudios sobre la democracia. Justamente este trabajo pone de relieve la convergencia de ambas y su pertinencia para México. En cuanto a la metodología, los ejes para realizar esta investigación fueron un enfoque comparatista (Hantrais, 2008; Osterle, 2002), con una perspectiva del análisis de las políticas públicas, considerando sus procedimientos de participación y transparencia (Parsons, 2008; McGee, 2009; Bobbio, 2008). De esta manera, se llevó a cabo un análisis documental (sobre todo documentos oficiales y de las corporaciones), entrevistas con funcionarios y especialistas, así como una revisión bibliográfica sobre el tema. Asimismo, se examinaron las legislaciones de los tres países sobre la materia y se realizó un seguimiento de los diarios nacionales al respecto.

Este texto está conformado por tres secciones: en la primera se analizan los casinos, su legislación y el aspecto impositivo. Se estudia la transparencia y el carácter público y social de las políticas. En la segunda sección, se examina la política de las loterías, su legislación y participación democrática. Asimismo, el carácter público, los beneficiarios de las loterías y la atención que otorgan al problema de la dependencia o adicción al juego (ludopatía). En un tercer bloque, se examina comparadamente el conjunto de las políticas públicas para la industria del juego, desde la 
óptica de la democracia. De igual modo, se plantean conclusiones y recomendaciones para emprender reformas de las políticas públicas en México, a la luz de la comparación con los otros dos países de Norteamérica.

\section{CASINOS: LEGISLACIÓN Y FISCALIDAD PARA LA EQUIDAD}

En Estados Unidos destaca el hecho de que, como federación, las legislaciones corresponden a los estados. Contrariamente a la percepción popular, solamente en diecinueve entidades la industria de los casinos es privada. ${ }^{2}$ Para tener una idea clara de su impacto sobre la economía y las finanzas públicas, los 443 casinos comerciales contribuyeron con 5200 millones en impuestos (2006). ${ }^{3}$ Así, los casinos están sujetos a controles estrictos e impuestos rigurosos, por ejemplo, Michigan impuso un 18 por ciento de los ingresos, además del 1.25 por ciento como pago municipal de servicios. Otros estados, como Illinois e Indiana, han establecido escalas de tasas de impuestos, en función de los ingresos de los casinos (desde un 15 a un 70 por ciento).

Por otra parte, cabe destacar que en 1988 se promulgó la Ley Federal de Casinos Indígenas: The Indian Gaming Regulatory Act, iniciativa federal en beneficio de grupos indígenas. Asimismo, es oportuno subrayar que existe un control de los casinos para evitar que los contamine el crimen organizado. En efecto, rigurosas legislaciones, como la Laundering Control Act de 1986, previenen el lavado de dinero. Además, se evita al crimen organizado por el hecho de que los casinos pertenecen a grandes hoteles o grandes compañías que cotizan en la bolsa, las cuales son verificadas por la Securities and Exchange Commission, así como por agencias federales y provinciales. ${ }^{4}$

En lo que respecta a Canadá, la prohibición del juego concluyó en 1969, cuando el código penal permitió a los gobiernos provinciales el uso de loterías para financiar programas sociales. En efecto, la Ley C-150, emitida por el entonces ministro de Justicia, Pierre Elliot Trudeau, permitió la industria del juego en "beneficio de obras de caridad" (Stevens, 2005). La ley se aprobó y discutió plural y democráticamente en el Parlamento. De este modo, Canadá mostró un aspecto central de su industria del juego: creó organismos públicos que incluyeran tanto a las loterías como a los casinos. Así, los casinos son casi en su totalidad públicos; ${ }^{5}$ es decir, la industria del juego se

\footnotetext{
${ }^{2}$ En treinta y seis estados no es comercial; entre éstos se encuentran los que cuentan con mayor población, como California, Florida, Nueva York y Texas.

${ }^{3}$ Generaron ganancias de más de veintisiete mil millones de dólares en 2003 (AGA, 2004).

${ }^{4}$ Sin embargo, algunas ONG, como Casino Watch, han señalado la existencia de vacíos legales en algunos estados (o límites en las pérdidas en el juego), aprovechados por el crimen organizado para el lavado de dinero.

${ }^{5}$ Solamente ocho son administrados por empresas privadas.
} 
concibe integralmente: para beneficio de los programas sociales, así como para coadyuvar en el desarrollo del país. En virtud del principio de descentralización, la industria del juego opera exclusivamente bajo el control de los gobiernos provinciales (Stevens, 2005). ${ }^{6}$

El modelo canadiense de la industria del juego ha permitido a las provincias de este país desarrollar sus políticas públicas, ya que los gobiernos provinciales aumentan sus ingresos sin elevar los impuestos (Klassen y Cosgrave, 2002). Éste ha sido un aspecto central del modelo canadiense, pues ha establecido un consenso tanto entre los partidos de conservadores, como entre los liberales para seguir manteniendo con carácter de públicos los casinos (y las loterías), de tal modo que se obtengan los ingresos de las arcas públicas sin aumentar los impuestos.

Para ejemplificar sobre la industria canadiense del juego, en Quebec, la empresa estatal Loto-Québec administra la lotería y los casinos de la provincia, generando dividendos importantes para el gobierno. En efecto, Quebec creó esta compañía pública en 1969 para organizar la industria de la lotería y en 1992 el Consejo de Ministros del gobierno aprobó la creación de casinos del Estado, administrados por esa misma compañía, con la filial Société des casinos du Québec (véase el cuadro 1).

\begin{tabular}{|c|c|}
\hline \multicolumn{2}{|c|}{$\begin{array}{c}\text { Cuadro } 1 \\
\text { LOTERÍA PÚBLICA EN LA PROVINCIA DE QUEBEC }\end{array}$} \\
\hline Loto-Québec (2009) & $\begin{array}{l}\text { Ingresos (millones de dólares canadienses) } \\
1455.75 \text { (egresos para el Estado y la comunidad) }\end{array}$ \\
\hline Dividendos al gobierno de Quebec & 1252.0 \\
\hline Lucha contra el juego compulsivo & 31.2 \\
\hline Impuestos & 132.0 \\
\hline Ayuda a la acción comunitaria autónoma* & 15.8 \\
\hline Patrocinio de eventos & 14.2 \\
\hline Organismos sin fines de lucro (bingos) & 18.0 \\
\hline Colección artística & 0.5 \\
\hline
\end{tabular}

En cuanto a los casinos en México, la ley sobre la industria de juego ilustra muy bien las contradicciones del marco legal: su nulo talante democrático y en particular

\footnotetext{
${ }^{6}$ Cabe mencionar la formación de sociedades interprovinciales de lotería, como la Western Canada Lottery Corporation (WCLC), en cuya administración participan representantes de cada provincia.
} 
su uso político. Según la ley, los juegos de azar están prohibidos en el país (artículo 1) desde el gobierno del presidente Lázaro Cárdenas. ${ }^{7}$ En los últimos diez años, se había discutido (sin estructurar ni propiciar un debate democrático) sobre la pertinencia de mantener esta prohibición, toda vez que, aprovechando la fragilidad del sistema legal, operaron las casas de juego y casinos, utilizando lo que Granados Chapa denominaba "la ambigüedad que caracteriza a la sociedad, en cuya extraña dialéctica no está vigente el principio de que lo no prohibido está permitido".

Algunos analistas, como Sergio Sarmiento (2011), solicitaron la anulación de la prohibición, para dar lugar a la apertura de casinos, argumentando que el juego es un asunto personal, en el que el gobierno no debe intervenir. Algunos más se opusieron porque generaría mayor criminalidad, pero estudios al respecto lo refutaron (Meixueiro, 2003). ${ }^{8}$

Durante 2003 y 2004, entrevisté a funcionarios para conocer la dirección que el gobierno federal planeaba, sin encontrar objetivos oficiales claros. Entonces, sin consulta previa, se expidió una intempestiva modificación legal en 2004: el Reglamento de la Ley Federal de Juegos y Sorteos. ${ }^{9}$ Los permisos han propiciado una extendida proliferación de casinos en el país. Este crecimiento anárquico ha acarreado tal desorganización de estos centros que existen muchas casas de apuestas que funcionan ilegalmente en el país. ${ }^{10}$

En 2011, la Secretaría de Gobernación (Segob) indicó la existencia de 561 casinos "legales" que operan con veintisiete permisos, además de los irregulares. ${ }^{11}$ A diferencia de otros países, en México, apenas a partir de 2008, el gobierno recauda impuestos por las mencionadas casas de apuestas (bingos y casinos). ${ }^{12}$ Sin embargo, esta anarquía imposibilita llevar a cabo una mínima recaudación de impuestos.

${ }^{7}$ Prohibió los casinos y clausuró tres de los más conocidos, dándoles otra función. El Casino de la Selva, en Cuernavaca, Morelos, se transformó en hotel; el de Agua Caliente, en Tijuana, se modificó y convirtió en el Centro Escolar Revolución, mientras que el Foreign Club, en Naucalpan, se convirtió en escuela militar.

${ }^{8} \mathrm{El}$ crimen ha crecido en el país en los últimos años, pero no necesariamente por los casinos; más bien por fallas estructurales del sistema de justicia que propician la impunidad (Rangel, 2011).

${ }^{9}$ Cabe mencionar que este reglamento fue declarado vigente por la Suprema Corte de Justicia de la Nación, en una controversia constitucional presentada en noviembre de 2004 por la Cámara de Diputados, que consideraba que el reglamento invadía sus atribuciones (El Universal, 22 de enero de 2007).

${ }^{10}$ Por ejemplo, en 2009, algunos senadores entregaron al secretario de Gobernación una lista de treinta y nueve casinos que operaban ilegalmente en el país (La Jornada, julio de 2009).

${ }^{11}$ La Segob informó que había sesenta casinos irregulares en el país, a pesar de que es obligación de esta secretaría sancionarlos y cerrarlos (artículos 8 y 12 de la ley).

${ }^{12}$ Se incluyó ese servicio entre las actividades gravadas con el (IEPS) Impuesto Especial a Empresas de Producción y Servicios con una tasa del 20 por ciento. 


\section{TRANSPARENCIA Y BENEFICIARIOS DE LOS CASINOS. \\ EL CARÁCTER PÚBLICO Y SOCIAL DE LAS POLÍTICAS}

En Estados Unidos, es pertinente destacar que los ingresos de los estados se invierten para propósitos claramente determinados. Por ejemplo, Nueva Jersey destina los ingresos de los casinos a la asistencia financiera para personas de la tercera edad y para discapacitados. El estado de Missouri designa un porcentaje para el tratamiento de la ludopatía, el 10 por ciento para los gobiernos municipales y el resto para un fondo educativo. Por lo que respecta al estado de Michigan, distribuye los ingresos de los casinos en un fondo de ayuda a las escuelas (el 45 por ciento) y el resto para la seguridad pública y para el desarrollo económico. El estado de Luisiana otorga el total de sus ingresos a un fondo para salarios y prestaciones para los profesores. Cabe señalar que el estado de Illinois asigna un porcentaje de los ingresos para las localidades que albergan un casino a un fondo de asistencia educativa. ${ }^{13}$

Por otra parte, como se mencionó, el gobierno estadunidense permitió el establecimiento de casinos con el fin de generar ingresos y promover el desarrollo económico para los grupos indígenas, así como para proteger estas empresas de la influencia del crimen organizado. Actualmente operan aproximadamente trescientos sesenta casinos que son administrados por doscientos veinte grupos indígenas (National Indian Gaming Commission, NIGC). Los ingresos de estos casinos ascienden a veintidós mil millones de dólares (cantidad mayor a la generada por los establecidos en Las Vegas). Con esta iniciativa federal, veintisiete entidades de Estados Unidos cuentan con casinos administrados por indígenas y el 40 por ciento de los grupos indígenas reconocidos por el gobierno federal operan casinos de manera autónoma.

Un estudio del impacto de esta industria sobre las comunidades indígenas indicó que los jóvenes adultos que antes migraban han regresado a las reservaciones; el empleo se ha incrementado un 26 por ciento y disminuyó un 14 por ciento el número de trabajadores pobres. Además, en un radio cercano a los casinos, el desempleo disminuyó (Conner y Taggart, 2009). Aunque algunos autores relativizan estas cifras, estudios de caso han mostrado los siguientes aspectos: en general, el impacto sobre los pueblos y sus gobiernos locales ha sido de beneficio mutuo. Esto se basa en la habilidad de los gobiernos locales para expandir los servicios sociales y fundar proyectos de capital. Muchos grupos indígenas que antes no poseían los recursos para satisfacer servicios básicos ahora operan diversos negocios, amplían los servicios sociales y cuentan con fondos para preservar su cultura.

\footnotetext{
${ }^{13}$ La información de esta sección se obtuvo de la National Conference of State Legislatures Survey of Commerce Clearing House Summary of State Tax Laws, 2004; asimismo, de información proveniente de la National Conference of State Legislatures.
} 
Otros estudios que han analizado el impacto sobre los programas educativos (Conner y Taggart, 2009) mostraron que los estudiantes de los pueblos indígenas que contaban con casinos tenían mejor desempeño que otros pueblos indios, debido a que tenían recursos para aplicar programas educativos extramuros. Se señala que aunque los casinos no aseguran el éxito de los estudiantes, sí han probado ser de gran utilidad para obtener recursos y mejorar la formación de los estudiantes; es decir, los fondos de los casinos financian múltiples iniciativas educativas comunitarias y, por lo tanto, contribuyen al desarrollo regional (Gallagher, 2005).

Así, percibimos una política democrática de la industria del juego, ya que la instalación de casinos en las comunidades indígenas las ha beneficiado claramente. De esta manera, como lo señala Touraine (2006: 240), la idea de democracia, en su origen, reivindicó para todos los ciudadanos la igualdad y la libertad que la sociedad les negaba. En efecto, esta política ha tenido éxito al ayudar a comunidades que históricamente han sido marginadas tanto en el discurso como en el despojo de sus tierras y propiedades, además del confinamiento del que fueron objeto (Wright, 2008).

Por lo que respecta a Canadá, debido al éxito experimentado en Estados Unidos, los grupos indígenas canadienses pugnaron por permisos similares. A diferencia de Estados Unidos, donde la iniciativa fue federal, en Canadá se llevaron a cabo negociaciones con las provincias, algunas de las cuales, como Alberta, han autorizado la participación como "recipient charity for revenus" para casinos en reservaciones indígenas, de acuerdo con el documento "First Nations Gambling Policy in Canada" (citado en Kelly, 2001). Asimismo, la provincia de Saskatchewan autorizó administrar los casinos de manera conjunta en 1995 (Kelly, 2001).

Por lo que respecta a México, como ya se señaló, el gobierno derechista (PAN) autorizó la apertura de casinos sin consulta pública ni discusión en el Congreso y repentinamente. El entonces secretario de Gobernación, Santiago Creel, emitió docenas de permisos para la operación de casas de apuesta (casinos) algunos días antes de dejar su cargo. Tiempo después confesó que éstos se otorgaron bajo la presión de compañías televisoras, en el contexto de las elecciones. Cabe destacar que los permisos otorgados fueron tan irregulares que el entonces presidente Calderón intentó anular las auditorías correspondientes previstas por la Auditoría Superior de la Federación y la Secretaría de la Función Pública (El Universal, 14 de enero de 2008). De esta manera, Calderón solicitó a la Suprema Corte de Justicia de la Nación acotar las facultades de estas instituciones para fiscalizar los permisos de las casas de apuestas emitidos por la Segob. Los beneficiarios de los permisos emitidos fueron el Grupo Caliente, ${ }^{14}$ Televisa

\footnotetext{
${ }^{14}$ De Jorge Hank Rohn, a través de diversas empresas. Ese grupo maneja setenta y siete centros de apuestas
} remotas y otras tantas salas de sorteos de número. 
(Apuestas Internacionales), ${ }^{15}$ Impulsora de Centros de Entretenimiento de las Américas (perteneciente al Consorcio Internacional de Espectáculos) y Eventos Festivos de México de Olegario Vázquez Raña. Se aprecia que los beneficiarios representan poderosos e influyentes grupos. ${ }^{16}$ Aunque éstos dicen ayudar al país, vía la creación de empleo, se observa que estos permisos (gratuitos) se otorgaron en una coyuntura política que obedeció a favores e intereses políticos. ${ }^{17}$

En el transcurso de la investigación, se solicitó información a la Segob para conocer información básica acerca del número de casinos registrados, su ingreso y la aportación que éstos hacen en materia de impuestos, pero se negó una respuesta. ${ }^{18}$ Esta actitud ilustra la opacidad dominante en la industria del juego en México, con la complicidad, particularmente, de los casinos, situación que contrasta con la transparencia de la información pública y accesible en Estados Unidos y Canadá.

El hecho de que la industria del juego se desarrolle en beneficio de poderosos grupos y sobre la ley, remite a la imagen de Biff $\mathrm{H}$. Tannen de la película Back to the Future, en la que este personaje roba un almanaque con los resultados deportivos del futuro, por lo que apuesta y se vuelve rico, poderoso y controla los casinos. ${ }^{19}$ Él vive por encima de la ley, que obedece a sus caprichos. De esta manera convierte a Estados Unidos (Hill Valley) en un lugar violento, deshumanizado y sin ley. ¿Qué mejor imagen que ese imperio del juego y de la fuerza para ilustrar la existencia de los casinos en México? Bajo el esquema adoptado en nuestro país, las leyes y el interés público están sujetos a quien posee el poder (y ahora incluso la industria del juego).

\section{LOTERÍAS: LEGISLACIÓN Y PARTICIPACIÓN DEMOCRÁTICA DE LAS POLÍTICAS}

Desplegar una política democrática de la industria del juego implica varios principios: prioridad del bien público, transparencia, equidad, participación e inclusión. La inclusión de las poblaciones marginadas (como las indígenas) contribuye a democratizar la sociedad y a darle cohesión social. ¿Qué función tienen las loterías en América del Norte respecto de estos principios?

\footnotetext{
${ }^{15}$ Empresa creada el 21 de febrero de 2005, tres meses antes de recibir sesenta y cinco permisos para apuestas electrónicas y otros tantos para sorteos de número. La filial Play City controla veinticinco establecimientos, donde maneja máquinas tragamonedas.

${ }^{16}$ Aunque la información al respecto es contradictoria, una muestra más de la opacidad de la industria.

${ }^{17}$ La Asociación de Permisionarios de Juegos y Sorteos, formada en 2007, informó que en 2012 la industria ofrecía cuarenta mil empleos formales y ciento cincuenta mil informales.

${ }^{18}$ Esta institución respondió que requería una "denominación o razón social, representante legal y las razones de la petición" (correo enviado por Suemy Míriam Velázquez Torres de la Segob, en octubre de 2010).

${ }^{19}$ Se trata de la película Volver al futuro II de Robert Zemeckis (1989).
} 
En Estados Unidos, las loterías son estatales y desarrollan claramente estos elementos de una política democrática: bajo un auténtico esquema de federalismo, cada estado decide si autoriza o no la creación de agencias públicas de lotería. Así, la mayoría de los estados las han establecido para explotar y administrar la industria (North American Association of State and Provincial Lotteries, NASPL). Conviene destacar que la decisión de reformar las constituciones estatales para permitir loterías y el establecimiento de estas agencias se llevó a cabo con base en una consulta pública (o referendo), la mayoría de las veces con una participación nutrida de la población.

\begin{tabular}{|c|c|}
\hline \multicolumn{2}{|c|}{$\begin{array}{c}\text { Cuadro } 2 \\
\text { CONSULTAS SOBRE LA INDUSTRIA DEL JUEGO EN ESTADOS UNIDOS }\end{array}$} \\
\hline Estado & Consulta \\
\hline Tennessee & $\begin{array}{l}\text { El referendo de } 2002 \text { apoyó (con un } 58 \text { por ciento) la creación de The Tennessee } \\
\text { Education Lottery. }\end{array}$ \\
\hline Wisconsin & $\begin{array}{l}\text { Referendo en } 1987 \text { para autorizar lotería, aprobado con un } 65 \text { por ciento de } \\
\text { los votos. } \\
\text { Referendo para continuar la lotería estatal (1993) aprobado con un } 72 \text { por } \\
\text { ciento de los votos. }\end{array}$ \\
\hline Vermont & Referendo en 1976 para establecer una lotería estatal, el 76 por ciento lo aprobó. \\
\hline Colorado & $\begin{array}{l}\text { En 2000, mediante referendo se aprueba la Multi-State Lotteries Act con un } \\
53.3 \text { por ciento. }\end{array}$ \\
\hline Georgia & $\begin{array}{l}\text { En 1992, la población aprobó mediante referendo modificar la Constitución y } \\
\text { establecer la lotería pública. }\end{array}$ \\
\hline Indiana & $\begin{array}{l}\text { En el referendo de 1988, la población aceptó (con un } 62 \text { por ciento) la Lottery } \\
\text { Act que establece la Hossier Lottery operada por el estado. }\end{array}$ \\
\hline Kentucky & $\begin{array}{l}\text { En } 1988 \text { se realiza un referendo con la participación de } 1.2 \text { millones de votos } \\
\text { (el } 60 \text { por ciento) a favor de la lotería pública. }\end{array}$ \\
\hline Michigan & Referendo en 1972 para aprobar la lotería estatal, con un 66 por ciento de los votos. \\
\hline Virginia Lottery & $\begin{array}{l}\text { El } 57 \text { por ciento votó a favor de crear la lotería pública en } 1987 . \\
\text { En 2000, más del } 80 \text { por ciento aprobó un cambio constitucional, creando el Lottery } \\
\text { Proceeds Fund que dedica la totalidad de los ingresos a la educación pública. }\end{array}$ \\
\hline
\end{tabular}

Cabe destacar que estas consultas se han utilizado para determinar a los beneficiarios de la industria en varios estados (véase el cuadro 2), por ejemplo, Oregon consultó a los electores para que eligieran entre la seguridad y la educación, ganando la segunda 
opción. ${ }^{20}$ Las loterías son independientes, se auditan cada año de manera independiente y son supervisadas por comisiones bipartidistas aprobadas por el Senado; además, éstas eligen a los directores de las loterías (por ejemplo, la Missouri Lottery Commission).

En cuanto a México, la administración del ex presidente Fox propuso una reforma (2003) para modificar la Ley Orgánica de la Lotenal. ${ }^{21}$ Con dicha modificación, su director general (nombrado por el presidente) tendría facultades plenas para decidir el destino de los fondos de esta institución. Así, la directora en turno decidió, en 2004, entregar el 50 por ciento a la federación y el 50 por ciento al fideicomiso Transforma México. ${ }^{22}$ Fueron bastante claras las redes de corrupción por las asignaciones de directores con compromisos partidistas y corporativistas. De este modo, la generación de fondos y su manejo han sido muy turbios, así como la utilización de sus recursos y los criterios de distribución. Estas condiciones se han traducido en un bajo rendimiento de la Lotería Nacional (Lotenal); como se observa en el cuadro 3, en promedio, las corporaciones estatales en Estados Unidos generan ingresos por casi un 25 por ciento de sus ventas; incluso los dividendos de países pequeños de Centroamérica son significativos, contrariamente a México, donde se registran pérdidas. ${ }^{23}$

\begin{tabular}{|lc|}
\hline \multicolumn{2}{|c|}{ Cuadro 3 } \\
\hline \multicolumn{2}{|c|}{ EJEMPLOS DE COMPAÑÍAS DE LOTERÍA ESTATALES Y SU APORTACIÓN AL ERARIO } \\
\hline Institución & Ingresos para el Estado en 2009 (en millones de dólares) \\
\hline Connecticut Lottery Corporation & 283.00 \\
Massachusetts State Lottery & $951.2(2006)$ \\
Texas Lottery Commission & 043 \\
Kentucky Lottery & $204.4(2006)$ \\
Michigan Lottery & 688 \\
Lotería Nacional para la Asistencia & Funciona con pérdidas significativas \\
\hline $\begin{array}{l}\text { Pública de México (Lotenal) } \\
\text { Fuente: Elaboración propia, con información que cada organismo proporciona a la North American Association } \\
\text { of State and Provincial Lotteries. }\end{array}$ \\
\hline
\end{tabular}

${ }^{20}$ En 2008, la Measure 62 proponía destinar el 15 por ciento de la lotería a un fondo de seguridad pública (Public Safety Fund for Crime Prevention, Investigation, Prosecution). Sin embargo, esta propuesta fue rechazada con un 60 por ciento de los votos, por lo que el dinero se destina exclusivamente a la educación (Oregon Lottery).

${ }^{21}$ La Lotería Nacional en México se fundó en el siglo XVIII y ha sido administrada por el gobierno federal desde entonces.

${ }^{22}$ Asociación fundada por la esposa del ex presidente, Marta Sahagún, y dirigida entonces por Elena Valdés Ruiz, hermana de la entonces directora de Lotería Nacional.

${ }^{23}$ Por ejemplo, en El Salvador, la Lotería Nacional generó 773 millones de dólares en 2010 (RDES, 2010). 
El farragoso reglamento de la Ley de juegos de 2004 privatiza las loterías, ya que trata (artículos 91 al 153) sobre los permisos para celebrar sorteos. Llama la atención que el capítulo 4 hable de "los sorteos transmitidos por los medios de comunicación masiva" y "los centros de apuestas remotas", es decir, se preveía que los permisos se otorgaran a compañías televisoras o con los medios financieros para utilizarlas. Así se concretó una tendencia de privatización en beneficio de compañías televisoras. ${ }^{24}$

En 2012 se informó que la situación de la Lotenal era peor de lo que sostenía el gobierno, la cual, hasta entonces, reportaba ganancias de sesenta millones de dólares anuales. La misma Lotenal informó que opera con pérdidas desde el primer año de gobierno de Vicente Fox. ${ }^{25}$ El documento explica que estas pérdidas (calculadas en 1230 millones de pesos) obedecen a "la intensa competencia de empresas privadas y la proliferación de casinos y casas de juego, algunas ilegales"; es decir, la Ley de juegos tuvo en los hechos la entrega a compañías privadas la explotación de la industria, ocasionando que la Lotenal opere con significativas pérdidas (Garduño y Méndez, 2012).

\section{Lotería: el bien común frente a la corrupción}

Los beneficiarios de las loterías en Estados Unidos han sido principalmente los programas educativos. Por ejemplo, la Kentucky Lottery, por medio de un proceso democrático, lo destina a la educación. En cambio, en 1988, la lotería de Florida estableció programas de becas, así como programas de alfabetización para adultos y educación inicial. A su vez, la de Vermont destina sus ingresos a la Vermont Education Fund. En Nuevo México, la lotería pública estatal aporta el cien por ciento del programa de becas College Scholarship Tuition Fund. La del estado de Nueva York remite la totalidad de los ingresos a la educación pública, es decir, 2595 millones (en 2008). ${ }^{26}$

En Tennesse, los trescientos millones anuales que ingresan se destinan a la educación media y las universidades (a través de la Tennessee Education Lottery). Los fondos restantes se invierten en proyectos de educación básica. Tennessee es uno de los tres estados que garantiza constitucionalmente que los ingresos por concepto de la lotería se inviertan en programas específicos de educación. ${ }^{27}$ Así pues, las loterías (y en general el juego) en Estados Unidos han sido aprobadas por la población vía

\footnotetext{
${ }^{24}$ Televisa creó la empresa de lotería Multijuegos, la cual previó obtener doscientos millones de dólares en 2007 (El Universal, 13 de febrero de 2007).

${ }^{25}$ Diagnóstico presentado por Lotenal y la sнycr a la Cámara de Diputados (diarios nacionales, 14 de febrero de 2012).

${ }^{26}$ Con información brindada por cada agencia de lotería mencionada.

${ }^{27}$ Con información de la Tennesse Lottery.
} 
referendos que no sólo legitiman y regulan la industria, sino que le dan una dirección al establecer prioridades para el beneficio de la comunidad.

Uno de los más exitosos programas de las loterías lo desarrolló el estado de Georgia: el Helping Outstanding Pupils Educationally (HOPE). Es un programa de becas para la educación media; más de un millón de estudiantes han sido beneficiados con éstas en los últimos cinco años (Rubenstein, 2001). El programa HOPE (cuyo costo fue de 640 millones de dólares en 2009) ha ayudado a estudiantes afroamericanos y otros grupos con rezago en las instituciones educativas de Estados Unidos. De esta manera, la población escolar afroamericanos aumentó 33 por ciento; el porcentaje de aprobados en los exámenes gubernamentales (SAT) pasó de 25 a 75 por ciento, y en general han mejorado sus calificaciones. Además, desde 1993, con el programa Hope más de 188000 estudiantes de colegios técnicos han resultado beneficiados, mejorando así su formación para el mercado laboral. Se estima que con este tipo de becas disminuya el abandono escolar en las universidades. Gracias al éxito de este programa, varios estados adoptaron estrategias similares con sus respectivos ingresos de la lotería. ${ }^{28}$

\begin{tabular}{|c|c|c|}
\hline \multicolumn{3}{|c|}{$\begin{array}{c}\text { Cuadro } 4 \\
\text { INDUSTRIA DEL JUEGO EN CANADÁ }\end{array}$} \\
\hline & Ingresos de 2009 & Beneficiarios \\
\hline $\begin{array}{l}\text { British Columbia Lottery } \\
\text { Corporation }\end{array}$ & 1082.0 millones & $\begin{array}{l}\text { Programas de salud, educación, } \\
\text { comunitarios; organismos de caridad; } \\
\text { gobiernos municipales y programas } \\
\text { contra ludopatía }\end{array}$ \\
\hline Alberta Lottery Fund & $\begin{array}{l}\text { En } 2011,1390 \\
\text { millones de dólares } \\
\text { sólo de lotería }\end{array}$ & $\begin{array}{l}\text { Fondo de desarrollo para indígenas } \\
\text { ( } 115 \text { millones), tecnología (105), } \\
\text { desarrollo rural (42.6), organismos } \\
\text { comunitarios (148.2), educación } \\
\text { (113.6), transporte (255), salud (450) }\end{array}$ \\
\hline $\begin{array}{l}\text { (OLG) Ontario Lottery and } \\
\text { Gaming Corporation } \\
\text { (controla lotería y casinos) }\end{array}$ & $\begin{array}{l}3800 \text { millones de } \\
\text { dólares, de los cuales } \\
1670.8 \text { millones } \\
\text { provenían de casinos }\end{array}$ & $\begin{array}{l}1900 \text { millones a la economía local, } \\
\text { ayuda a hospitales, programas contra } \\
\text { ludopatía, ejercicio físico, deportes, } \\
\text { actividades culturales y recreativas a } \\
\text { través del Ontario Trillium Foundation }\end{array}$ \\
\hline
\end{tabular}

En Canadá, la industria ha financiado áreas prioritarias (como la educativa y el medio ambiente); asimismo, ha mantenido un vínculo con los sectores sociales y comu-

\footnotetext{
${ }^{28}$ Información obtenida de la Georgia Lottery y de la Georgia Student Commission.
} 
nitarios. De igual modo, ha permitido un desarrollo regional; es decir, ha aprovechado la industria para ejercer -como afirma Morris (2001)- una política pública cuyo propósito final es servir al interés público (véase el cuadro 4).

En Canadá, la industria la controlan los gobiernos provinciales. Por ejemplo, en Quebec, Loto-Québec creó una nueva filial en 1997 para la administración de bingos: la Société des bingos du Québec ( $\mathrm{SBQ}$ ). Esta filial colabora con organismos sin fines de lucro, los cuales se abocan a los sectores de la salud, de servicios comunitarios y sociales. Así, todos los ingresos de las ventas de los productos de los bingos se distribuyen entre los organismos participantes. En 2011-2012, se generaron más de cinco millones de dólares para los 653 organismos participantes y se destinaron importantes sumas anuales a los grupos comunitarios y asociaciones civiles, contribuyendo así al desarrollo regional ${ }^{29}$ (véase el cuadro 1 ).

En cuanto a México, el fideicomiso Transforma México (2004) benefició a ochenta y siete organizaciones (supuestamente de la sociedad civil), pero varias de carácter religioso (como Provida), o grupos con filiación partidista y universidades privadas. Además, se financió a la Fundación Vamos México. ${ }^{30}$ Es decir, hubo irregularidad por conflicto de intereses, nepotismo, criterios partidistas y se remitieron fondos a instituciones que no lo ameritaban. Durante el gobierno de Felipe Calderón, los escándalos de corrupción continuaron en la Lotenal; por ejemplo, el Diario de Yucatán denunció un intento de soborno para realizar propaganda política a favor de candidatos del PAN en Campeche, que sería pagada con recursos de la Lotenal. Algunos periodistas señalaron que ese incidente era un indicio de la utilización partidaria e ilícita con fondos de la lotería pública. ${ }^{31}$ Además, recientemente, se denunció un fraude en Pronósticos Deportivos. ${ }^{32}$ En suma, se observa que los actos de corrupción en México se contraponen al interés público que desarrollan las loterías estadunidenses y canadienses.

\section{Políticas Contra el JUEGo COMPULSIVO O LUDOPATía}

Los jugadores compulsivos representan un problema importante de salud pública, ya que se trata de una patología que ocasiona en las personas la ruina económica, la

${ }^{29}$ Los responsables de las setenta y tres salas de juegos de bingo reciben el 8 por ciento de las ventas de bingo en red (Loto-Québec, 2012).

${ }^{30}$ En junio de 2004, la prensa señalaba el desvío de fondos por más de cien millones de pesos de la Lotenal, mediante el fideicomiso Transforma México.

${ }^{31}$ Denuncia del director editorial del Diario de Yucatán, Luis Alberto González Uribe (en abril de 2009), contra el entonces director de la Lotería Nacional, Miguel Ángel Jiménez (Zuckerman, 2009).

${ }^{32}$ Directivos y empleados de Pronósticos Deportivos planearon un fraude por ciento sesenta millones de pesos (diarios nacionales, 19 de julio de 2011). 
desintegración familiar, incluso el suicidio. Algunos estudios muestran que las personas pobres juegan más y compran más boletos de lotería (Samuel, 2002).

Por este motivo, para la opinión pública canadiense existe una actitud crítica hacia el gobierno por intervenir en el sector. Algunos intelectuales han formulado una oposición, por ejemplo, John Ralston Saul (2005), quien habla de un "Estado crupier". Sin embargo, como observamos, el sistema canadiense desmiente esta descalificación, pues desarrolla una misión social. Por ejemplo, presta atención al juego compulsivo, ya que destina cantidades importantes de dinero a la atención de personas con esa patología. Además, financia proyectos de investigación con las universidades para estudiar el fenómeno y realiza la difusión de campañas de prevención y sensibilización de este problema en la población.

En Estados Unidos, algunas agencias de lotería gubernamentales cuentan con programas de prevención y tratamiento de este problema. En cambio, en México, como consecuencia del caos de la industria y los intereses a los que responde, no existe una política pública al respecto ni siquiera por parte de las corporaciones que la explotan; de esta manera, los jugadores compulsivos sufren las consecuencias de su patología, siendo abandonados a su suerte.

\section{Políticas públicas para la industria del juego}

Es necesario poner la industria del juego en la perspectiva de la democracia. En este sentido, el presente estudio debe verse desde esta óptica. Octavio Paz dijo que sin democracia no puede haber modernidad económica; hemos observado que la industria del juego en México no se apega a los principios de la democracia y -como consecuencia- no es una industria moderna. En virtud de las evidencias de la investigación desarrollada, resulta de gran relevancia considerar los siguientes aspectos de una política al respecto.

\section{El carácter público de la industria}

Es fundamental que con una perspectiva democrática la industria adquiera y desarrolle un carácter público, es decir, para la comunidad en general. ¿Cómo asegurar este carácter público? Se observó que la participación de la sociedad civil es fundamental para decidir sobre la utilidad de los fondos y la gestión de casinos y lotería. Esta estrategia asegura que no se contamine por el corporativismo, los intereses partidistas o que sea manipulada por los grupos de poder. 
El desarrollo de la industria de la lotería en Estados Unidos y Canadá ofrece lecciones evidentes a México. Por una parte, para cuestionar el maniqueísmo prevaleciente en el país entre lo privado y lo estatal, así como el discurso de demonización de la participación gubernamental que desvirtúa el beneficio público de la industria. Por la otra, muestra de manera concreta el desarrollo de instituciones que han asegurado la legalidad, la seguridad, así como el bienestar de los ciudadanos de manera participativa e inclusiva; es decir, se deben promover políticas que aseguren una prioridad a lo que Locke (2008) llamó interés civil, y que incluso en la actualidad los profesionales contables reconocen como interés público. ${ }^{33}$

Como se observó, la mayor parte de los estados invierten en educación, por lo que, por un lado, han desarrollado políticas públicas intersectoriales, pues existe un vínculo entre el sector del juego y los beneficiarios, como la educación. Por el otro, el carácter público de la industria asegura que los fondos se destinen a este sector de manera consensuada.

\section{Transparencia (democracia como poder visible)}

Para Bobbio (2008) en la democracia deben desaparecer los poderes invisibles. Si el régimen democrático ha sido definido como el gobierno controlado por el pueblo, ¿cómo estaría controlado si estuviese escondido?, se pregunta Bobbio. Como él lo señala, la descentralización contribuye a que los ciudadanos vigilen mejor las instituciones. Se observa que tanto en Estados Unidos como en Canadá la industria es descentralizada, dentro de un marco de auténtico federalismo y con instituciones independientes, mientras que en México es centralizado (bajo el control de la sнyср y de la Segob).

En este sentido, convendría diseñar instituciones políticas y sociales para mejorar la comunicación de las sociedades democráticas (Parsons, 2008). Por ejemplo, una industria con tanta opacidad (reforzada por las instituciones gubernamentales en México) permite no sólo la evasión fiscal (que el gobierno prácticamente promovió), sino el fortalecimiento de redes de corrupción. Asimismo, la opacidad permite los lazos con el crimen organizado e impide la más mínima regulación, no digamos ya un mínimo beneficio social. Por el contrario, la transparencia está asegurada por el carácter público de las instituciones (como los casinos en Canadá y las loterías en Estados Unidos), las cuales cuentan incluso con información detallada en sus sitios de Internet. Como se indica en estudios recientes, la transparencia y la participación del público sirve para alcanzar metas de legitimidad y una sustantiva calidad de gobernanza en

\footnotetext{
${ }^{33}$ Véase la definición de "public interest" de la International Federation of Accountants (IFAC).
} 
las agencias (Coglianese, Kilmartin y Mendelson, 2008). Esta legitimidad es particularmente necesaria para el funcionamiento de las agencias públicas del juego.

\section{Políticas públicas democráticas}

Wayne Parsons (2008) afirmó que, para concebir políticas públicas, es importante rebasar los aspectos coyunturales y abocarse a la consecución de objetivos. Parsons y otros especialistas insisten en ir más allá de la gestión para proveer mejores servicios a través de una mayor democracia (Hirst, 1996). El propósito de las políticas públicas -nos recuerda Parsons- es el pleno desarrollo de los individuos en la sociedad, el desarrollo del consenso y la conciencia social, así como la legitimidad, más que la prestación de bienes y servicios. Cabe señalar la siguiente paradoja: en Estados Unidos y Canadá, en el ámbito académico y político no existe un reconocimiento explícito del papel democrático de la industria del juego. Incluso autores como Lasswell, que defendieron políticas democráticas, quedaron limitados por sus contradicciones (Farr y Hacker, 2006). Estas contradicciones explican que los teóricos conservadores valoren poco una industria que tradicionalmente han censurado y la participación estatal que han demonizado. De ahí la pertinencia de subrayar el carácter democrático de esta industria en América del Norte.

Otros autores han subrayado la trascendencia del referendo como instrumento de una democracia participativa para cristalizar una decisión colectiva. Mendelsohnn y Parkin (eds., 2001) advierten, por ejemplo, que el referendo se ha incrustado en el corazón de los sistemas de las democracias representativas. En efecto, con la dinámica social de una democracia se establecen políticas participativas a partir de mecanismos como el referendo. Esta consulta popular libre, consciente e informada, reafirma el derecho de consulta y participación de los ciudadanos (McGee, 2009). Así, como Wagschal (1997) señaló, la democracia directa construye las políticas públicas. Aun cuando en México se habla del referendo, raramente se lo vincula con los derechos de los ciudadanos sobre decisiones determinantes de políticas, por ejemplo, las relativas a la industria del juego, como se lleva a cabo en Estados Unidos.

Michael Apple (2003) define la democracia como el proceso de renovación de las instituciones, y las de la industria del juego no serían la excepción. Estas instituciones se renuevan democráticamente con transparencia y participación para asegurar el bienestar colectivo. Para la ideología de derecha dominante, la democracia representa la libertad de ser propietario de casinos y loterías. Esto supone que las personas sólo son consumidoras de boletos de lotería y fichas en casinos. Pero la democracia significa más bien que los ciudadanos tengan oportunidades significativas 
de participar en las políticas públicas, como lo señalan varios autores, entre ellos Chomsky (1994). Como se advierte, incluir las políticas relativas al juego es esencial en el contexto actual de crisis económica.

\section{El papel de la sociedad civil}

Autores como Cohen y Arato (2000) y Hirst (1996) se han pronunciado por establecer un puente entre la sociedad civil y el Estado. Las democracias desarrollan instituciones y una sociedad civil fuerte; es decir, existe la necesidad de construir instituciones sociales cuyo vínculo con las asociaciones civiles sea transparente, abierto y responsable (Barnett, 2011). Para ir más allá de los grupos que restringen el poder del Estado, o de quienes pretenden reforzarlo, es preciso restituir el poder de la sociedad civil dentro de una legalidad y unas instituciones públicas renovadas. Esto se observa en las políticas canadienses, en las que los organismos comunitarios desempeñan un papel central para organizar y beneficiarse de los bingos. Como lo señala Smith (2003) en el contexto canadiense, involucrar al público no contribuye únicamente a mejorar los servicios, sino que resuelve conflictos y responde a las demandas de participación de la gente.

Los objetivos de las políticas públicas de las sociedades liberales contribuyen a la consecución de una democratización progresiva (Parsons, 2008). Sin embargo, ¿cómo se definen estos objetivos? Como vimos, por medio de las consultas se adopta el consenso, los principios de equidad y se buscan medidas para la inclusión social. Asimismo, observamos que las políticas fiscales y sociales coinciden para apoyar las políticas educativas al inyectar cuantiosos fondos, que son de capital importancia en un contexto de crisis o estancamiento del financiamiento de la educación. En este sentido, las políticas de este sector en México son incomprensibles y resultan un fracaso social sin este objetivo fundamental de democratización, esencial en el difícil momento que transita el país.

Ante la falta de políticas, las decisiones gubernamentales son influidas por los medios de comunicación, que a su vez son manipulados por los grupos usufructuarios de la industria (Burstein, 2008). Se constata que las políticas en torno al juego deben ser convergentes con otras políticas públicas de salud, educación y trabajo, de tal modo que tengan un impacto social significativo y que a su vez contribuyan a la construcción democrática en el país. En este sentido, el estado de opacidad (e incluso de corrupción) observado en la Lotenal muestra que en México no se han reformado estas instituciones ni renovado la administración en procesos políticos, parte fundamental de una transición democrática, como lo propone Dreyfus (2004). Es revelador 
que esa industria haya sido negociada con el corporativismo de la educación, en perjuicio tanto de la institución, como de la educación misma. ${ }^{34}$ Por el contrario, en Estados Unidos, a través de mecanismos democráticos, las loterías públicas apoyan sustancialmente a la educación.

En suma, tomando en cuenta los beneficiarios, los recursos y los principios (bajo los parámetros establecidos por Osterle, 2002), es claro que comparativamente las políticas públicas en Estados Unidos y Canadá apuntan a la equidad social; mientras que en México, a la inequidad.

\section{Conclusiones}

Los casinos, loterías y bingos no se pueden dejar, literalmente, al azar. Se requieren políticas públicas de la industria del juego, con carácter democrático, pues éstas han probado varias ventajas: se regula la industria en función del bienestar de la población. En Estados Unidos y Canadá se ha constatado que, contrariamente a las críticas de algunos sectores acerca de la participación gubernamental, ésta asegura un bienestar público y previene los impactos negativos de la industria (como el juego compulsivo y la prevención del crimen). Así, la transparencia y la participación de los ciudadanos permite que la explotación de la industria se haga con base en un federalismo justo, en el que estados y provincias administran y reciben los beneficios de la industria (McGee et al., 2003). Los dividendos de loterías y casinos se utilizan en áreas prioritarias de interés público, principalmente la educación.

Además, en el caso de Estados Unidos, los casinos para los pueblos indígenas ofrecen recursos y posibilidades de desarrollo a una población que históricamente ha sido marginada. Los intereses de los estados se han olvidado y la participación ciudadana ha sido menospreciada. En suma, la ausencia de una política y la acción gubernamental ha tenido por resultado una imposición de intereses mezquinos. Esta dinámica ha reproducido y acentuado la concentración de la riqueza.

Mientras que en Estados Unidos las loterías y en Canadá, tanto casinos como loterías, son administradas por organismos gubernamentales bajo políticas claras, la situación en México muestra una ausencia de una política pública. Una legislación contradictoria y una supuesta "regulación" que ha beneficiado a pocos grupos de poder, además de que ha hecho de la lotería un negocio no solamente privado, sino que beneficia a un pequeño y poderoso grupo. Esto ha producido el crecimiento caótico

\footnotetext{
${ }^{34}$ La entonces dirigente del SNTE, Elba Esther Gordillo, informó sobre un acuerdo con Felipe Calderón en 2006, que incluía el control de dicho sindicato sobre la Lotenal (diarios nacionales, 30 de junio de 2011).
} 
de la industria y la concentración de la industria del juego en beneficio de pocas manos; un ingreso casi nulo para el gobierno y con escaso impacto para el desarrollo nacional. Esto ha desmentido a quienes se oponían a la participación del Estado, argumentando que el juego es una cuestión personal. No obstante, se trata de un asunto social, pues se trata de una industria que por su naturaleza debe ser pública, para dirimir su dirección y supervisión de manera transparente (véanse los cuadros 5 y 6).

\begin{tabular}{|c|c|c|c|}
\hline \multicolumn{4}{|c|}{$\begin{array}{c}\text { Cuadro } 5 \\
\text { COMPARACIÓN DE LAS POLÍTICAS DEMOCRÁTICAS DE LA INDUSTRIA DEL JUEGC }\end{array}$} \\
\hline & Transparencia & Decisión de ciudadanos & Organización \\
\hline México & $\begin{array}{l}\text { La opacidad genera } \\
\text { corrupción. }\end{array}$ & No existió consulta pública. & $\begin{array}{l}\text { Centralista (vía la sнуср } \\
\text { y la Segob). }\end{array}$ \\
\hline $\begin{array}{l}\text { Estados } \\
\text { Unidos }\end{array}$ & Asegura transparencia. & $\begin{array}{l}\text { Se realizaron referendos } \\
\text { para la apertura de loterías } \\
\text { y para destinar los ingresos. }\end{array}$ & $\begin{array}{l}\text { Cada estado dirige su } \\
\text { industria. Los casinos } \\
\text { indígenas son de } \\
\text { competencia federal. }\end{array}$ \\
\hline Canadá & $\begin{array}{l}\text { Transparencia } \\
\text { obligatoria. }\end{array}$ & $\begin{array}{l}\text { Democracia vía el } \\
\text { Parlamento. }\end{array}$ & $\begin{array}{l}\text { Cada provincia dirige } \\
\text { su industria. }\end{array}$ \\
\hline
\end{tabular}

\begin{tabular}{|c|c|c|c|}
\hline \multicolumn{4}{|c|}{$\begin{array}{c}\text { Cuadro } 6 \\
\text { COMPARACIÓN DE LAS POLÍTICAS DEMOCRÁTICAS DE LA INDUSTRIA DEL JUEGO }\end{array}$} \\
\hline & Beneficiarios & $\begin{array}{l}\text { Atención al juego } \\
\text { compulsivo }\end{array}$ & $\begin{array}{l}\text { Prevención contra } \\
\text { la delincuencia } \\
\text { organizada }\end{array}$ \\
\hline México & Grupos poderosos. & $\begin{array}{l}\text { La industria no atiende el } \\
\text { juego compulsivo. }\end{array}$ & $\begin{array}{l}\text { No hay prevención } \\
\text { para evitar el crimen } \\
\text { organizado. }\end{array}$ \\
\hline $\begin{array}{l}\text { Estados } \\
\text { Unidos }\end{array}$ & $\begin{array}{l}\text { De la lotería, en especial la } \\
\text { educación. De los casinos, } \\
\text { los beneficios vía impuestos. }\end{array}$ & $\begin{array}{l}\text { Algunos estados ofrecen } \\
\text { atención. }\end{array}$ & $\begin{array}{l}\text { Preventiva, vía } \\
\text { legislaciones y } \\
\text { transparencia. }\end{array}$ \\
\hline Canadá & $\begin{array}{l}\text { Debido a que es pública, } \\
\text { existen diversos beneficiarios. }\end{array}$ & $\begin{array}{l}\text { Provee atención, } \\
\text { investigación y sensibilización. }\end{array}$ & $\begin{array}{l}\text { Preventiva } \\
\text { (es pública). }\end{array}$ \\
\hline
\end{tabular}


En México se sabía que la Lotenal era una empresa con bajo rendimiento, pero ahora sabemos que es fuertemente deficitaria. Es una organización que continúa las reglas del régimen mexicano centralizado y autoritario. Es poco transparente, burocrática y de lazos estrechos con el poder, ya que el nombramiento de su director es facultad presidencial (incluso a la merced de negociaciones oscuras con el corporativismo). Como lo señala Carothers (2005), una democracia débil es aquella en la que existe una pobre representación. En el 2000, a pesar de la alternancia de partidos políticos en el poder, estas condiciones persistieron. No hubo cambios de políticas, ni de visión y tampoco hubo una transformación, sino más bien signos de degeneración. El mismo Carothers (2006) criticó las interpretaciones falaces de las transiciones lineales y automáticas, como se quiso presentar a México. Una verdadera transición se materializará cuando se reformen instituciones (Dreyfus, 2004) y los ciudadanos incidan en las políticas y, por lo tanto, que éstas los beneficien (Chomsky, 1994).

El lamentable atentado del 25 de agosto de 2011, ocurrido en Monterrey contra el Casino Royale (que causó cincuenta y dos muertes) confirmó, patente y trágicamente, los señalamientos que nuestra investigación había identificado. En efecto, tal y como se desarrolla la industria del juego en México, está a merced del crimen organizado, ya sea por el lavado de dinero o por ser un blanco idóneo para la extorsión; sobre todo en centros que operan con ilegalidad, que ciertamente proliferan en el país.

Además, las instituciones que se supone deberían controlar la industria son parte de ese caos, pues las condiciones que prevalecen en la industria del juego son insostenibles, contraproducentes y requieren un cambio radical de visión y organización, así como de las instituciones que supuestamente la regulan. En efecto, la Segob ha sido incapaz de controlar la explosión caótica que ella misma generó y que incluso participa en su corrupción y conflicto de intereses. ${ }^{35}$ Cuando los principios de gobierno se corrompen, las mejores leyes se vuelven malas, escribió Montesquieu (2008: 196). Por eso los cambios que se requieren no deben limitarse a cuestiones legislativas, sino a principios que soporten nuevas políticas. Una gobernanza democrática de las instituciones de la industria del juego contrarrestaría la corrupción (Bailey, 2006).

Con el gran contraste entre las políticas en torno al juego en México y sus vecinos del Norte, México acentúa una vez más la brecha entre ricos y pobres. Esta situación pone de manifiesto que, contrariamente a los promotores del TLCAN, que auguraban riqueza para México, son más bien los programas sociales emanados de políticas públicas democráticas que generan financiamiento (como la industria del juego) las que equilibrarían a la sociedad, volviéndola más equitativa y, por ende, más democrática.

\footnotetext{
${ }^{35}$ Por ejemplo, Correa Méndez, director de Juegos y Sorteos de la Segob, autorizó cincuenta permisos a casinos un día antes de renunciar (diarios nacionales, 24 de septiembre de 2011).
} 
La firma del TLCAN se consumó con argumentos que apuntaban al mejoramiento de la economía mexicana, e incluso se decía que disminuiría la asimetría entre México y sus socios con dicho tratado. Sin embargo, la naturaleza de aquél fue estrictamente comercial y su impacto ha sido raquítico como promotor del crecimiento económico y de la creación de empleos (Stiglitz, 2004). A la luz de las políticas de la industria del juego (o ante la ausencia de éstas), es evidente que se acentúa la asimetría entre México y sus socios en el TLCAN, pues mientras que en Estados Unidos y Canadá son equitativas, en México no lo son (según Osterle, 2002). Transformar la industria no contradice los términos de dicho tratado, por el contrario, la reformaría con normas y principios similares para atraer turistas de esos países a casinos seguros y transparentes.

Cabe considerar, además, que los otros dos países de Norteamérica cuentan (y destinan) mayores fondos para la educación y para los programas sociales. Las jugosas sumas que aporta la industria del juego son complementarias a los presupuestos asignados, que a su vez son mucho mayores que los asignados por México (según la OCDE). ${ }^{36}$ Es decir, nuestro país, aun cuando requiere más de dichos ingresos, no los aprovecha debido a la dinámica actual de la industria del juego.

Es preciso puntualizar que la desigualdad en la sociedad mexicana es antigua y se remonta a los orígenes mismos del país. Humboldt señalaba la desigualdad extrema en la sociedad mexicana. Incluso políticos y analistas reconocen la desigualdad y la pobreza, pero hay una clara ausencia de estrategias para abordarla y atacarla. De continuar la política actual de la industria del juego, la desigualdad seguirá acrecentándose. Se ha vuelto un lugar común de académicos y políticos señalar las desigualdades del país, pero son escasas las iniciativas, y menos aún las políticas que se pongan en práctica para enfrentar la abismal desigualdad y la distribución de la riqueza. Touraine (2006) formuló que la desigualdad se ha transformado en un dualismo estructural. Es decir, la incapacidad de América Latina de lograr una democracia social basada en el reconocimiento de los derechos de los ciudadanos marginados. En este contexto, para atacar este dualismo estructural del que habla Touraine, es esencial recurrir a la industria del juego para mejorar las condiciones económicas de los más necesitados y desposeídos, como los grupos indígenas.

En el país, al acrecentar las diferencias y la acumulación económica y de poder, las políticas alejan a México de la democracia. La negligencia ante la ley de la industria (que es inadecuada), la ausencia de políticas públicas y la influencia de los llamados poderes fácticos han causado que no se aprovechen los atractivos ingresos de

\footnotetext{
${ }^{36}$ Las inversiones a la educación por cada estudiante en Estados Unidos fueron 15812 dólares, mientras que en México fue de 2875 dólares (OCDE, 2009). Para Canadá fueron 25197 dólares, incluyendo los gastos de investigación (Statistiques Canada, 2009).
} 
la industria del juego para beneficio público. Se necesita un cambio radical de la industria del juego en México que aproxime estándares de seguridad, equidad y democracia a los existentes en el resto de América del Norte. Es inadmisible que la Lotenal opere con pérdidas que representan una carga para los mexicanos, cuando debería de ser lo contrario: una industria al servicio de los ciudadanos.

El secreto para emprender este cambio es la democracia, para construir una modernidad económica, como lo señaló Paz. Se ha hablado mucho de la redistribución de la riqueza en México, pero poco se ha hecho para solucionarla. Voltaire observó que el arte de gobernar consiste en tomar la mayor cantidad posible de dinero de una categoría de ciudadanos para dárselo a otra. En Estados Unidos y Canadá los gobiernos utilizan la industria del juego justamente bajo esta lógica de redistribución al sector educativo y a los sectores marginados, como los grupos indígenas.

\section{RECOMENDACIONES}

Como consecuencia de los trágicos sucesos en el Casino Royale de Monterrey, diversas voces se manifestaron por la clausura de casinos (Gershenson, 2011). Sin embargo, la opción legislativa de prohibir los juegos es, en definitiva, poco realista y en los hechos perpetuaría la industria ilegal que funciona en la actualidad. Otros se han pronunciado por que el Estado garantice únicamente la seguridad de casinos o, debido al desorden prevaleciente, se supone que sólo se necesita una regulación de los permisos existentes o terminar su "reventa" ${ }^{37}$ Estas medidas serían evidentemente útiles, pero el problema no estriba en la gestión de expedientes o contratar policías para los casinos. Más aún, es indispensable romper el vínculo de los casinos con los grupos de poder y cambiar radicalmente la visión y los principios de esa industria. En este sentido, sería recomendable construir políticas públicas en México tomando en cuenta los siguientes elementos.

\section{Independencia de una industria pública}

Para preservar la autonomía del poder político y económico del país, los directivos responsables de la industria (ya sea estatal o federal), no deben ser nombrados por el presidente o los gobernadores ni en función de cuotas partidistas. En este sentido, conviene, para poner fin a las contradicciones de la ley y su reglamento, así como su

\footnotetext{
${ }^{37}$ La ley estipula la regulación en el artículo 17 del reglamento, y la reventa de permisos la prohíbe el artículo 15 de aquélla.
} 
profundo impacto negativo, derogar el reglamento emitido en 2004. Las condiciones y las razones expuestas ameritan que se sustituyan con una ley constitucional que establezca el carácter público de manera inequívoca e inviolable.

\section{Participación democrática}

La gestión y la supervisión de la industria deben corresponder a la sociedad civil. Señalemos la eventual participación de rectores, académicos, periodistas, organismos civiles (auténticos y reconocidos) y de representantes de los grupos indígenas. De esta manera es imprescindible contar con una empresa pública (sin un aparato burocrático) estrictamente controlada y que atienda las demandas sociales. La organización de una consulta referendaria daría legitimidad frente a los poderosos grupos que la usurpan.

\section{Definición clara de los beneficiarios}

Las consultas ayudan a enfocar las necesidades. Los referendos en varias entidades de Estados Unidos han indicado una preferencia de las poblaciones a destinar los ingresos a la educación. En este sentido, se recomienda llevar a cabo consultas para determinar el destino de las ganancias. Se aconseja (una vez aceptado en una consulta) que la citada ley estipule que los fondos se destinen a la educación. Asimismo, sería conveniente reservar algunos casinos para grupos indígenas en regiones del país donde sea factible.

\section{Atención a la ludopatía}

La legislación debe establecer que la industria contribuya a sensibilizar a la población, y que profesionales de la salud atiendan a personas que sufren de una dependencia patológica de los juegos, ya que esta conducta destruye su patrimonio familiar, su integridad psicológica e incluso presionaría a la gente a cometer delitos.

\section{Participación de los gobiernos estatales}

Como se observó, en Estados Unidos y en Canadá los estados o provincias dirigen la industria del juego, principalmente las loterías. Se podría hablar de una paulatina descentralización a mediano plazo, aunque lo esencial es establecer una estructura de 
gobernanza democrática y participativa que asegure los principios de independencia y transparencia con el involucramiento de los estados.

\section{BibLIOGRAFíA}

Aceves VelázQuez, Wendy

2011 “Casinos, más que un asunto moral”, La Gaceta, 5 de septiembre.

American Gaming Association (aga)

2004 "State Information", en <http://www.americangaming.org/industry-resources/state-information>.

Apple, Michael

2003 The State and Politics of Education, Nueva York, Routledge.

BAILEY, JOHN

2006 "Corruption and Democratic Gobernability in Latin America. Issues of Types, Arenas, Perceptions, and Linkages", San Juan, conferencia presentada en la Latin American Studies Association, 15-18 de marzo.

BARNETT, ANTHONY

2011 "Why Does Democratic Reform Matter?", en Revisiting Associative Democracy, Londres, Lawrence and Wishart, pp. 24-29.

BOBBio, NORBERTO

2008 El futuro de la democracia, México, FCE.

Burstein, PAUL

2008 Public Opinion, Public Policy, and Democracy: Old Expectations and New. Handbook of Politics, Nueva York, Springer.

CAROTHERS, THOMAS

2006 "How Democracies Emerge. The 'Secuencing Falacy", Journal of Democracy, vol. 18, no. 1, enero.

2005 "What Really Lies Venid Challenges of Deepening Democracy and Establishing the Rule of Law?", Londres, conferencia presentada en New Challenges in State Building, 21 de junio. 


\section{CHOMSKY, NOAM}

1994 Secrets, Lies and Democracy, Tucson, Odonian Press.

Coglianese, Cary, Heather Kilmartin y Evan Mendelson

2008 "Transparency and Public Participation in the Rulemaking Process. A Nonpartisan Presidential Transition Task Force Report", University of Pennsylvania Law School.

Cohen, J.L. y Adrew Arato

2000 Sociedad civil y teoría politica, México, FCE.

Conner, Thaddieus W. y William A. Taggart

2009 "The Impact of Indian Gaming on Indian Education in New Mexico", vol. 20, no. 3 , otoño.

DREYFUS, F.

2004 L'Administration dans le processus de transition vers la démocratie, París, Publications de la Sorbonne.

Evans, William y Julie TOPOLESKi

2002 "The Social and Economic Impact of Native American Casinos", NBER, Working Papers Series, en <www.nber.org/ papers/w9198>, consultada el 2 de octubre de 2011.

FARR, J. y J. HACKER

2006 "The Policy Scientist of Democracy: The Discipline of Harold Lasswell", American Political Science Review, vol. 100, no. 4, noviembre.

Gallagher, M.

2005 "Gaming Tribes Cash in: Profits to Boost Education, Improve Quality of Life", The Albuquerque Journal, 2 de enero.

Garduño, Roberto y EnRiQue Méndez

2012 "Lotenal opera con pérdidas desde el sexenio de Fox", La Jornada, 14 de febrero.

Gershenson, ANTONIO

2011 “Casinos... y otras cosas", La Jornada, 4 de septiembre. 
GONZÁlEz RuIZ, ÉDGAR

2009 "Lotenal, caja chica de la derecha", Contralínea, 26 de abril.

Granados Chapa, Miguel Ángel

2009a "Lotería Nacional para el PAN", Reforma, 5 de abril.

2009 b "Casinos ilegales y evasores", Reforma, 27 de agosto.

HANTRAIS, LiNDA

2008 International Comparative Research, Londres, Macmillan.

HiRst, PAUL

1996 Democracy and Civil Society, Oxford, Blackwell.

Hugh, Dellios

2004 "After almost Seven Decades, Legalized Casino Gambling May Return to Mexico", Chicago Tribune, 17 de agosto.

Instituto Ciudadano de Estudios de La InSEguridad (ICESi)

2005 Estudio sobre la posible legalización de los casinos en México, México, ICESI.

JORNADA, LA

200917 de julio.

KELLY, RoBIN

2001 "Firts Nations Gambling Policy in Canada", Gambling in Canada Research Report, no. 12.

Klassen, T.R. y J. Cosgrave

2002 "Look Who's Addicted to Gambling Now", Policy Options, nos. 43-46, julioagosto.

LiNer, Ross PHILIP

2004 The Impact of the Three Land Based Indian Casinos In Louisiana, Lincoln, Nebraska, iUniverse.

LOCKE, JOHN

2008 Traité du gouvernement civil, París, Flammarion. 


\section{LOTO-QuÉBEC}

2012 Annual Report, Quebec, Loto-Québec.

McGeE, BRANT

2009 “The Community Referendum: Participatory Democracy and the Right to Free, Prior and Informed Consent to Development", Berkeley of Journal of International Law, vol. 27, no. 2, pp. 570-635.

McGee, Rosemary et al.

2003 Legal Frameworks for Citizen Participation, Syntesis Report. Logo Link, en <http:/ / siteresources.worldbank.org/INTPCENG/Resources/SynthesisRep-Web.pdf>.

McGovern, Patrick y Peter Yacobucci

1999 "Lasswellian Policy Sciences and the Bounding of Democracy, WPSA", en <http: / / www.cddc.vt.edu/tps / e-print/Lasswell.PDF>.

Mendelsohnn, Matthew y Andrew Parkin, eds.

2001 Referendum Democracy: Citizens, Elites and Deliberation in Referendum Campaigns, Nueva York, Palgrave.

Meixueiro Nájera, Gustavo

2003 Los casinos y el crimen: la experiencia en los Estados Unidos, México, Cámara de Diputados, Estudios de Desarrollo Regional.

Montesquieu, Charles Louis de Secondat, señor de la Brède y barón de 2008 De l'Esprit des lois, París, Flammarion.

MORRIS, L.

2001 "Public Policy", en M.E. Crahan et al., eds., The Oxford Companion to Politics of the World, Oxford, Oxford University Press.

OCDE

2009 Regards sur l'éducation 2009: les indicateurs de L'OCDE, París, OCDE.

\section{Osterle, August}

2002 "Evaluating Equity in Social Policy. A Framework for Comparative Analysis Evaluation", vol. 8, no. 1, enero, pp. 46-59. 
PARSONS, WAYNE

2008 Análisis de políticas públicas, México, Flacso.

Ralston SAUL, JOHN

2005 The Collapse of Globalism, Toronto, Viking.

RANGel TORRIJO, Hugo

2011 Ideales y dimensiones de la democracia, México, Universidad de Guadalajara.

República de El SALVAdor (Rdes)

2010 "Lotería Nacional de Beneficencia. Resumen de Resultados", San Salvador.

Rubenstein, Ross

2001 Georgia's Hope Scholarship, Georgia, Young School of Policy Studies, Georgia State University.

SAMUEL, LEAH

2002 "Illinois Lottery: The Poor Play More" (issue), Chicago Reporter.

Sarmiento, Sergio

2011 "Cazar casinos", Reforma, 30 de agosto.

Secretaría de Gobernación (Segob)

1947 Ley Federal de Juegos y Sorteos, México, Segob.

SMith, BRUCE

2003 Public Policy and Public Participation Engaging Citizens and Community in the Development of Public Policy, Halifax, Health Canada.

SPILler, Alberto

2011 “Todos pierden”, La Gaceta, 5 de septiembre.

\section{Statistiques Canada}

2009 Investissements fédéraux dans l'éducation postsecondaire et la formation, Ottawa, Statistiques Canada.

STEVENS, R.

2005 "Legalized Gambling in Canada", Alberta Gaming Research Institute, en 
$<$ www.abgamblinginstitute.ualberta.ca/.../LegalizedGamblinginCanada. asp $>$, consultada el 15 de diciembre de 2010.

STIGLITZ, JOSEPH

2004 "The Broken Promise of NAFTA", The New York Times, 6 de enero.

Touraine, A.

2006 "Latin America, Two Opposing Solutions to Latin America's Two-Sided Problem", Envio, no. 304, noviembre.

UNIVERSAL, EL

2011 "El laberinto de los casinos", El Universal, 14 de septiembre.

200814 de enero.

200722 de enero.

200713 de febrero.

Vela, DAVID S.

2011 “Casinos... campañas en NL”, La Gaceta, 5 de septiembre.

Volpe, ANGelo A.

2004 “Tennessee State Lottery:How Will it Benefit Education in Our State?", en <http: / / iweb.tntech.edu/kosburn/ aaup/Volpe-remarks.htm>, consultada el 7 de diciembre de 2011.

WAGSCHAL, UWE

1997 "Direct 'Democracy and Public Policymaking'”, Journal of Public Policy, vol. 3, no. 17 , pp. 223-245.

Wright, Roland

2008 What Is America?, Toronto, Knopf.

ZuCKERMANN, L.

2009 “El PRI se sacó la lotería”, Excélsior, 3 de abril. 
